\title{
Fetal Disorder
}

National Cancer Institute

\section{Source}

National Cancer Institute. Fetal Disorder. NCI Thesaurus. Code C92719.

A non-neoplastic or neoplastic disorder which occurs in the fetus. 